\title{
Consumer Knowledge, Brand Image, Openness to Experience and Involvement: A Case in Cosmetic Consumption
}

\author{
Ya-Chen Lu' ${ }^{1}$, Kuan-Nien Chen ${ }^{2 *}$ \\ ${ }^{1}$ Bayer Taiwan Company Ltd., Taiwan \\ ${ }^{2}$ Kaohsiung Medical University, Taiwan \\ Email: dkkksj159@hotmail.com.tw, *wc@kmu.edu.tw
}

How to cite this paper: Lu, Y.-C. and Chen, K.-N. (2017) Consumer Knowledge, Brand Image, Openness to Experience and Involvement: A Case in Cosmetic Consumption. Journal of Cosmetics, Dermatological Sciences and Applications, 7 , 349-361.

https://doi.org/10.4236/jcdsa.2017.74031

Received: November 22, 2017

Accepted: December 25, 2017

Published: December 28, 2017

Copyright $\odot 2017$ by authors and Scientific Research Publishing Inc. This work is licensed under the Creative Commons Attribution International License (CC BY 4.0).

http://creativecommons.org/licenses/by/4.0/

(C) (i) Open Access

\begin{abstract}
The study adopted the theory of planned behavior (TPB) as research model to inspect what factors would influence consumers to purchase cosmetics by adding brand image, involvement, consumer knowledge and openness to experience to the model. A 7-point Likert scale questionnaire was designed to measure TPB items and totally 400 valid respondents were collected online. The results show that among the above, only "perceived behavioral control" has positive influence on intention of purchasing cosmetics. Neither attitude nor subjective norm has significant influence on purchasing intention. In addition, brand image and involvement have no significant influence on purchasing intention but consumer knowledge and openness to experience were found to have positive influence on purchasing intention.
\end{abstract}

\section{Keywords}

Theory of Planned Behavior, Cosmetics, Brand Image, Involvement, Consumer Knowledge, Openness to Experience, Consumer Behavior

\section{Introduction}

With the improvement of communication quality of product promotion, people begin to pursue better lives. For example, even in the bad economy, the consuming of cosmetics is still growing. People can get the information of cosmetics easily by the Internet. This helps consumers acquire more knowledge about cosmetics.

There are 59 percent of women who thought their appearance as important, which ranks higher than socializing with friends (53 percent), their career/job 
(49 percent) and fashion (19 percent) [1].

In Taiwan, many people are in pursuit of beauty and looking for the cosmetics to keep them young and pretty. With the information explosion, consumers check the ingredients, the efficacy and the toxicity of cosmetics carefully through the Internet, advertisements, and others. Nowadays, some consumers avoid buying the cosmetics which have some specific ingredients with potential toxicity [2].

In addition, it is essential for both cosmetic companies and marketing departments to understand their customers so that their demands can be satisfied. Although there have been many cosmetic researches, the relationship between consumer knowledge and cosmetic buying behavior has not been fully discussed yet. Consumers make the buying decisions by using their knowledge and information. The process of buying includes identifying what they need, searching the information and evaluating of criteria [3].

People in Taiwan are easily influenced by celebrities, friends and even someone who has relationship with them. Therefore, Taiwanese usually consider what brands the other people have, and like to buy those brands because they can be identified with others. Sometimes, cosmetic companies advertise and promote their brands aggressively to improve the exposure of their brands and strengthen brand image. Consumers are likely to have the consciousness that some brands are famous based on the brand image. They make the consumers to buy the cosmetics having good brand image.

Whether the consumers in Taiwan use the consumer knowledge to distinguish the information of cosmetics and then make purchasing decisions or they buy cosmetics only because of brand image is still a puzzle.

As consumers have higher degree of involvement in searching product information, they are more participative in the buying process, and value the buying decision prudentially. The involvement of consumers is various because everyone has different hobbies, value and motivation [1]. Sometimes, consumers can't distinguish the information on the packages exactly. For instance, if consumers have high involvement, they will search the information spontaneously. Consumers want to know the safety and efficacy of the nonprescription drugs and they will also ask opinion of the experts or other people [4]. In addition, cosmetics are a kind of products that consumers involve both in buying and using process [1].

There are various kinds of cosmetics in the market. Asides from the general cosmetics, there are cosmeceuticals which emphasize on the efficacy. Consumers who have high involvement will pay more attention on the information such as ingredients and efficacy and also ask the opinions of the experts or others spontaneously. That will affect their cosmetic buying process.

Openness to experience is one of the Big Five Model, and people who have higher degree of openness to experience are more curious to everything. They like to try and challenge new things. Cosmetic industry is an industry that varies from time to time. A product may be popular at this moment but eliminated soon after. As a result, cosmetic companies must release their new products con- 
stantly and try to attract consumers' attention. Hence, whether the consumers who have higher degree of openness to experience are willing to try new cosmetics, and then influence their buying decision is still a question for us.

The researchers will investigate how consumer knowledge, brand image, involvement and openness to experience affect consumers to buy cosmetics. Therefore, the researchers should consider them as the variables in our study.

\section{The Theory of Planned Behavior}

The Theory of Planned Behavior (TPB) was derived from the Theory of Reasoned Action (TRA) (Figure 1). The TRA utilized attitude and subjective norm to predict the subjects' behavioral intention, and then predict their specific behavior by their behavioral intention.

The interaction between subjective norm and attitude is complicated, and the TRA predict the intention directly without limitation [5]. Moreover, some behavior is beyond people's control. For example, they don't have enough time to finish the behavior or they don't have appropriate chance or situation. This will make the TRA unpredictable on the behavior exactly [6]. When people carry out the behavior which is probably to be unsuccessful and they also can't control the situation they face with. Then this behavior wouldn't be predicted by the TRA. To solve this, Ajzen proposed the further theory "the Theory of Planned Behavior (TPB)" (Figure 2) [7].

The TPB provides a practical research framework (Figure 3) that can let us understand the complicated human behavior. It has high precision to predict the behavior by using attitude, subjective norm and perceived behavioral control [8].

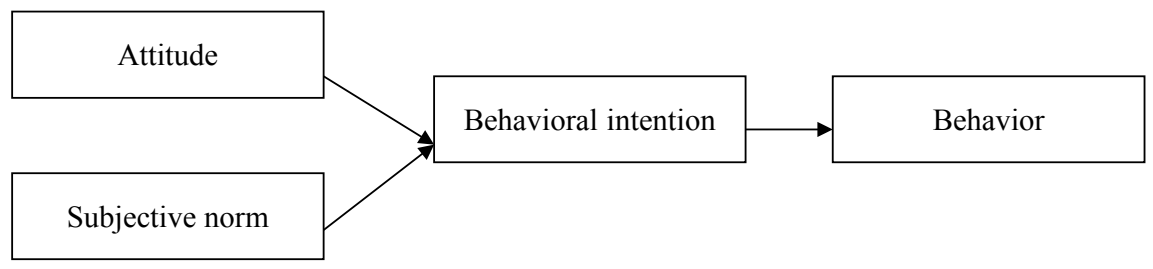

Figure 1. The theory of reasoned action. Source: Fishbein \& Ajzen (1975).

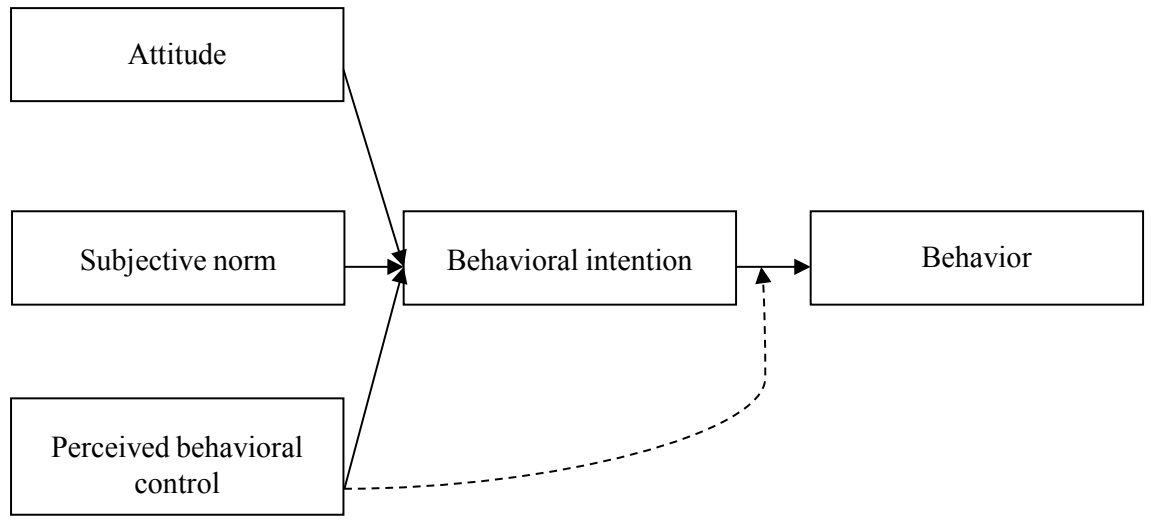

Figure 2. The theory of planned behavior. Source: Ajzen (1985). 


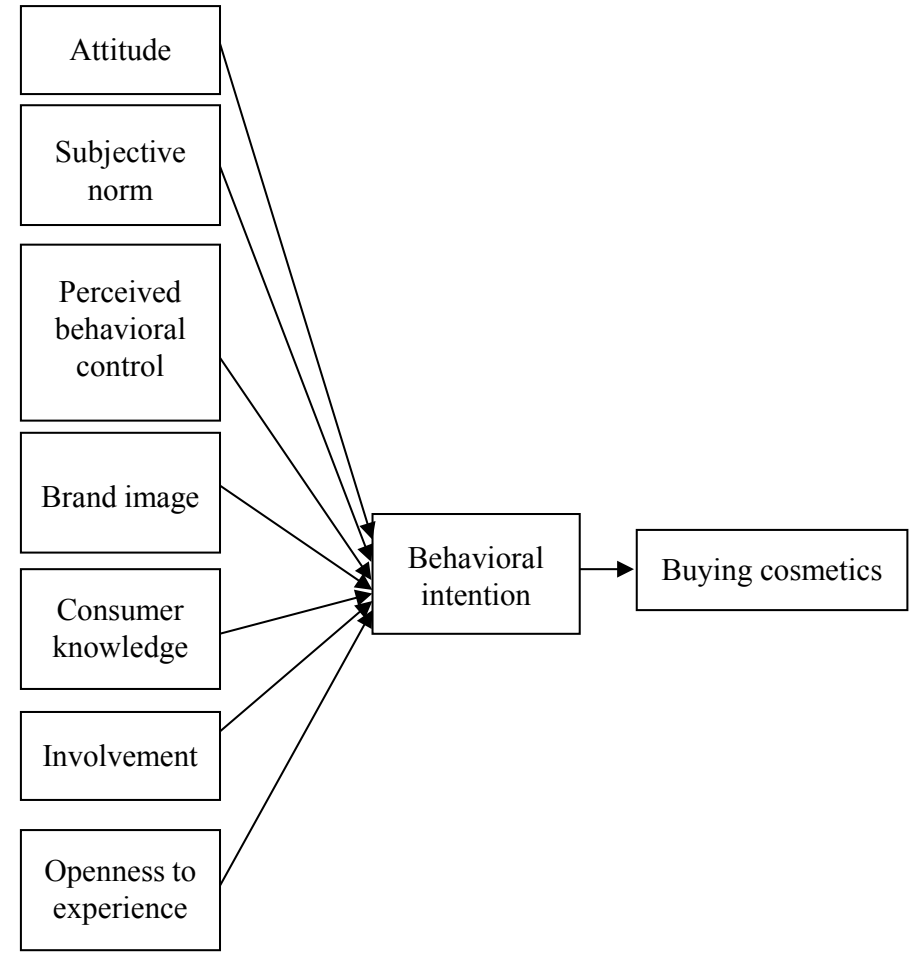

Figure 3. Research model.

For this reason, there are many scholars who have used the TPB as their research frameworks [9]. Pikturnienè and Mackelaite [10] use the TPB to compare consumers' attitude between buying the domestic skin care products and the international skin care products; Loureiro and Araújo discuss the factors that why people buy luxury goods; Kim and Karpova [11] explore why people want to buy counterfeits by using the TPB as a research model. Attitude refers to "the degree to which a person has a favorable or unfavorable evaluation or appraisal of the behavior in question". Subjective norm refers to "the perceived social pressure to perform or not to perform the behavior". Perceived behavioral control refers to "the perceived ease or difficulty of performing the behavior and it is assumed to reflect past experience as well as anticipated impediments and obstacles" [8]. Because consumers can't control whether they can buy cosmetics or not when they don't have enough time, money or chance, perceived behavioral control seems to affect consumers' buying intention. Therefore, the researchers used TPB as our research model.

\section{Consumer Knowledge}

Consumer knowledge is composed of familiarity and product knowledge. Familiarity refers to the accumulative experience that a consumer has, and product knowledge refers to the sum memory of product class information and rules that stored in a consumer's memory [12].

Brucks [13] classifies product class knowledge into three parts based on previous studies. The first category (subjective norm) measures a person's perception 
of how much he or she knows. The second category (objective norm) measures the amount of correlative knowledge, categories or organization which has been actually stored in a person's memory. The third category measures the correlative experience of buying or using the product. The third category is less to be used to associate with behavior directly because the third one only affects behavior when experience results in difference in memory. Therefore, the third category is seldom discussed when a habit is not associated with behavior. Subjective norm can be seemed a person's degree of confidence in his or her knowledge. Objective norm is the situation that a person really has the knowledge. Subjective norm and objective norm are different when a person can't assure how much he or she knows about the information.

For objective knowledge, it can be measured by checking a person's relative knowledge construct in his or her long-term memory. The understanding of objective knowledge can help us to know how decision makers' knowledge amount and contents influence the evaluation and strategies of the decisions. The measurement of subjective norm provides decision makers' systematic biases of choice evaluation and decisions [14].

Moorman [15] discusses how subjective knowledge influences consumers' choice and where consume search. When consumers don't have high objective knowledge, consumers who have high subjective knowledge would make the better decision such as buying healthier food than consumers who have low subjective knowledge. In addition, the study also proved that subjective knowledge affected where consumers search products and the quality of the products they choose, because consumers tend to behave to fit their subjective knowledge. Therefore, consumers' subjective knowledge can affect decision situations, where consumers buy products and the quality of products. Besides, Morven finds that adding knowledge as a predicator can improve the ability to predict consumers' purchasing behavior.

\section{Brand Image}

Brand is always an important factor for a company. Brand image can induce brand loyalty from consumers. Therefore, brand recognition begins an important issue for brand management [16] [17].

How to show brand image is a big issue for marketing. A good expression of brand can position a brand. The brand can be distinguished from the other brands. Brand image can influence sale volume directly. It can also influence the relationship between product lifecycle and sale. Hence, it's important for us to understand brand image, so that we can avoid implementing wrong product lifecycle strategies [18].

Brand image is brand personality or the reflection of products. What affect consumers to buy which brands is "the need of consumers" [19].

Park [18] classifies brand image into three parts: 1) functional needs are designed to satisfy consumers' external needs; symbolic needs are designed to sa- 
tisfy consumers' inner needs such as self-enhancement and role position; 2) experimental needs are designed to provide sensory pleasure, variety and sensory stimulation.

Consumers tend to buy the brands or products which others expect them to buy, and they also like to buy the same brands or products which others have, so that they can be recognized by others [20]. Cosmetics are sold in drug stores, department stores and shopping mall which are kinds of public places. Therefore, it is hypothesized that when consumers buy cosmetics in public, they will be affected by cosmetic brand image which will affect their buying decisions.

Godey [21] discusses how brand and the country-of-origin effect influence consumers' luxury goods purchasing decisions. The result displays that brand image has more powerful ways for consumers to buy the luxury goods than the country-of-origin effect itself. Zhan and Kim [22] discuss what factors affect Chinese to buy luxury fashion goods (such as perfume). Consumers living in China want to imitate celebrities or friends and to buy the specific luxury fashion goods. This would make them feel safe and confident because there are a lot of luxury cosmetics which can be seen in the market, and most people in Asia care others' thinking much. It is hypothesized that brand image influences the process of buying cosmetics.

\section{Involvement}

Consumers' involvement in products is widely used as one of the advertised strategies. Every consumer's decision-making process and situation of searching information are different with different degrees of involvement. Involvement refers to consumers who have causal or motivated variation when they are buying something or communicating with someone. Therefore, with different degrees of involvement, consumers' decision-making process is considerably different from comparing different brands, the time of making decisions or the degree of searching information [23].

Houston and Rothschild [24] categorize involvement into three types. Situational: the degree of involvement was evoked by special situation, and it was the temporary situation; enduring: consumers continually concern products when they were buying the products and it was a kind of stable and long-term situation; response: it can be considered the combination of situation and enduring, and it was the relative feeling of consumers to products or situations [1] [25].

Based on these studies, the researchers supposed that involvement affects consumers to buy cosmetics.

\section{Openness to Experience}

Openness to experience is one of the "Big Five", namely extraversion, agreeableness, conscientiousness, neuroticism and openness to experience, factors of personality. Openness to experience is a personality that describes the imagination, the sensibility for art and intellectual capability. Besides, it was also considered 
to have the relationship with knowledge and search of information [26]. Because people who have this personality are seen to accept new products easily, the researchers assumed that consumers who have higher openness to experience are prone to accept or buy cosmetics.

\section{Hypotheses}

Seven hypotheses for the study were provided as follows:

H1: Attitude has a positive effect on the purchasing intention of a cosmetic.

H2: Subjective norm has a positive effect on the purchasing intention of a cosmetic.

H3: Perceived behavior control has a positive effect on the purchasing intention of a cosmetic.

H4: Brand image has a positive effect on the purchasing intention of a cosmetic.

H5: Consumer knowledge has a positive effect on the purchasing intention of a cosmetic.

H6: Involvement has a positive effect on the purchasing intention of a cosmetic.

H7: Openness to experience has a positive effect on the purchasing intention of a cosmetic.

\section{Questionnaire and Instruments}

The researchers used TPB as the research model and extended it by adding "openness to experience", "consumer knowledge", "brand image" and "involvement". Such variables were developed to test the proposed model and hypotheses. Ajzen [8] suggested 7-point Likert scale to measure TPB items which can show what the respondents think clearly.

This study defines brand image as the image and the feeling of a brand. Brand image was measured by using five items (c.f., [11] [27] [28]) asking how important a brand for respondents.

Attitude was defined as the feeling of consumers when buying or using cosmetics. The researchers use three items to measure it (c.f., [29])

Involvement was defined as how respondents feel when they purchase cosmetics, and the researchers measured this variable by using four items (c.f., [30]).

Perceived behavioral control was defined as how respondents perceive that whether they can control themselves to purchase cosmetics or not, and the researchers used five items to test it (c.f., [29]).

Behavioral intention was defined as the degree of how respondents want to buy cosmetics, and the researchers used five items to measure it (c.f., [29]).

Consumer knowledge was defined as how the respondents think that they know cosmetic knowledge, and the researchers used five items to test it (c.f., [13]).

Openness to experience was defined as the respondents who have high openness to experience about many things and enjoy their life. The researchers 
measured it by using five items (c.f., [2]).

\section{Pretest}

The researchers collected 30 respondents to check whether they can understand the questionnaire. The respondents' ages ranged from 20 to 65 . We used Cronbach's $\alpha$ to measure the reliability, and the values of Cronbach's $\alpha$ were between 0.732 and 0.931 . All values showed high reliability.

\section{Sample and Data Collection}

The researchers collected the data through online-survey and spread the questionnaires by social media, Facebook and Line. The researchers totally collected 413 questionnaires. There were 13 invalid questionnaires. The response rate is approximately $96.8 \%$. The respondents' ages ranged from 20 to 65 , and both males $(24.3 \%)$ and females $(75.8 \%)$ were collected. The researchers also asked the education, the average income and the frequencies of purchasing cosmetics in the past years and the average cost on cosmetics per month.

\section{Data Analysis and Results}

This study used SPSS 20.0 to analyze the data by using exploratory factor analyses to check the validity and Cronbach's $\alpha$ to check the reliability. Principal component analyses were performed, and all factor had the KMO (Kaiser-Meyer-Olkin) which are larger than 0.7 [31]. One factor was extracted for each scale except perceived behavioral control which was extracted into two factors. The study deleted one item which belongs to another factor to insure the better quality for further analysis. Furthermore, the Cronbach's $\alpha$ were ranged from 0.783 to 0.923 , which showed high reliability.

The researchers applied Pearson's correlation to discuss the correlation between the variables and the behavioral intention. Cohen [32] suggested that a correlation above 0.5 is strong, 0.3 to 0.5 is moderate, 0.1 to 0.3 is weak and under 0.1 is none or very weak. The result showed that attitude, subjective norm, brand image and involvement didn't have significant correlation with behavioral intention. Perceived behavioral control, consumer knowledge, openness to experience had strong correlation with behavioral intention (Figure 4).

The result showed that brand image, involvement, attitude and subjective norm had no significant impact on behavioral intention (Table 1). Perceived behavioral control had positive association with intention $(\beta=0.143, p<0.001)$. Consumer knowledge had positive association with intention $(\beta=0.310, p<$ $0.001)$. Openness to experience had positive association with intention $(\beta=$ $0.089, p<0.05)$. Therefore, H3, H5 and H7 were supported. In the meantime, $\mathrm{H} 1, \mathrm{H} 2, \mathrm{H} 4$ and $\mathrm{H} 6$ were not supported.

\section{Discussion}

Based on the TPB framework, only perceived behavioral control influences the 


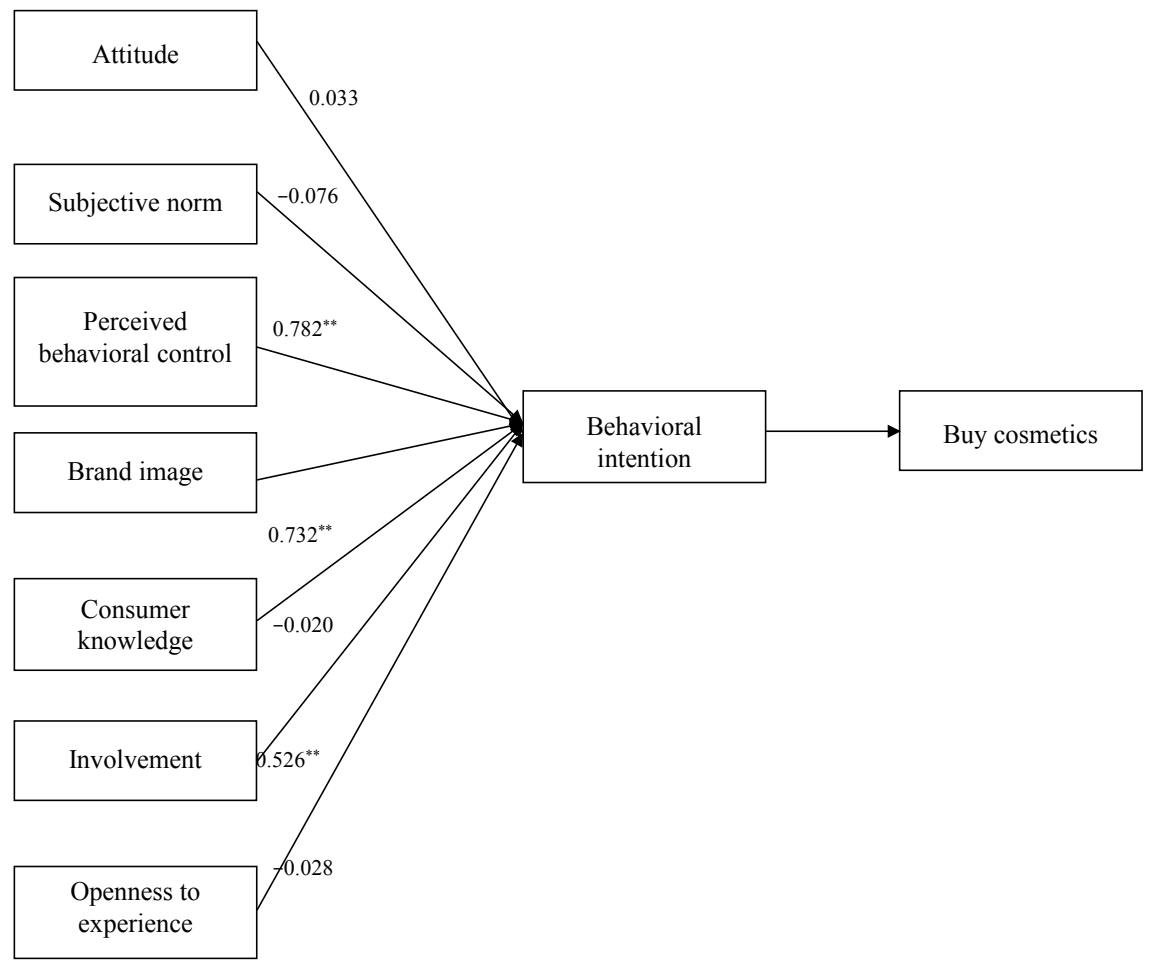

Figure 4. The result of Pearson's correlation. ${ }^{* *} p<0.01$.

Table 1. The results of multiple regression analysis.

\begin{tabular}{cccccc}
\hline Predictors & beta & $\mathrm{SE}(\mathrm{B})$ & $\mathrm{t}$ & $\mathrm{F}$ & $\mathrm{R}^{2}$ \\
\hline Brand image & -0.046 & 0.039 & -1.193 & $116.662^{* * * *}$ & 0.670 \\
Attitude & 0.069 & 0.048 & 1.441 & & \\
Involvement & -0.023 & 0.041 & -0.569 & & \\
Subjective norm & -0.028 & 0.041 & -0.686 & & \\
Perceived behavioral control & 0.143 & 0.012 & $12.126^{* * *}$ & & \\
Consumer knowledge & 0.310 & 0.045 & $6.919^{* * * *}$ & & \\
Openness to experience & 0.089 & 0.042 & $2.123^{*}$ & &
\end{tabular}

${ }^{*} p<0.05 ;{ }^{* *} p<0.01 ;{ }^{* *} p<0.005 ;{ }^{* * *} p<0.001$.

respondents to purchase cosmetics. The results were different from the previous study which showed that attitude positively influences the intention to purchase face and body care products [10]. Besides, subjective norm doesn't affect the intention to purchase cosmetics and this result was inconsistent with the previous study [2]. The results suggest that people purchase cosmetics depending on whether they have enough time and money. Their past purchasing experience or the obstacles they encounter also affect people to buy the products. On the other hand, whether they like to purchase cosmetics or not don't influence them. It might be that when they need cosmetics, even they don't like to execute the buying behavior, they still have to complete the purchasing. Also, subjective norm doesn't affect people to buy cosmetics, and maybe it was because buying 
cosmetics was a personal behavior. Therefore, people would not care other people's thinking much.

The study expanded the TPB by adding brand image, involvement, consumer knowledge and openness to experience. Surprisingly, brand image doesn't have significantly influence on purchasing intention, and it was different from the previous study which showed brand consciousness plays an important role in predicting Chinese consumers' attitude toward buying luxury products [22]. This might be that there are too many cosmetic brands in the market. The study didn't focus on the prices of cosmetics, so that the respondents may imagine the cosmetics the cheaper ones which they didn't care about brands too much and they also changed brands easily.

Involvement is also found not influence the intention of purchasing cosmetics. It is because cosmetics are a kind of Fast Moving Consumer Good (FMCG) products which belong to low involvement products [3]. It doesn't influence respondents' decisions to buy cosmetics. In addition, Guthrie and Kim [1] reported people had different levels of involvement would view brands differently, but the levels of involvement don't influence the intention of purchasing cosmetics, so, this might be another reason why brand image doesn't affect respondents to purchase cosmetics.

In the study, consumer knowledge has positively influence on intention of purchasing cosmetics, and this result can be explained by the previous study which reported subjective knowledge would affect where consumers bought products and what they bought, and then influence their choices to buy products [15]. This is an interesting finding, and the marketers or the cosmetic companies can utilize these findings to help themselves promote their products by giving more information about their cosmetics or trying to teach their customers more knowledge about the products.

Openness to experience was also found positively influence the intention of purchasing cosmetics, and this result is consistent with previous study which also showed that openness to experience would positively affect people to buy free-off cosmetics [2]. It can prove that people who have more this personality are easily to accept more things around them, and therefore they are easily to conduct the purchasing behavior. This result gives a suggestion that the cosmetic retailers and sellers can focus on consumers who seem to have the personality more, and give them some interesting introduction of the cosmetics may attract them to buy.

\section{Conclusions}

The purpose of this study is to investigate what factors will affect consumers to buy cosmetics. The researchers expanded the TPB by adding brand image, involvement, consumer knowledge and openness to experience.

In the TPB model, only perceived behavioral control has positive influence on the intention of buying cosmetics. It is more important for consumers to have 
enough time or money to accomplish the buying behavior in comparison with their preference or others' thinking. The cosmetic companies can provide the consumers more convenient ways such as cash on delivery or home delivery to make them feel the buying behavior.

In our study, consumer knowledge has more powerful impact on buying behavior than brand image. In comparison with the influence of brand image, whether consumers think they have sufficient cosmetic knowledge has more significant influence on buying intention. When consumers think they have higher consumer knowledge, they will have more confidence for their buying decision, and then it will make them have higher buying intention.

Openness to experience has positive influence on buying intention. People who have higher openness to experience have more intention to buy cosmetics due to their curiosity or because they are more willing to try new products.

These findings can give future researches or cosmetic companies some suggestions to understand why consumers buy cosmetics and how to make promotion strategies to attract consumers to buy cosmetics.

\section{Limitations of Study}

The samples were all collected in Taiwan, so that the results might be inconsistent because of different culture, people and environment. Besides, brand image and involvement in the study didn't show the influence on the intention of purchasing cosmetics. This could be caused by the study that didn't restrict the price factor of the cosmetics. Further research can investigate whether consumers have high involvement when they purchase luxury cosmetic brands, and therefore affect their intention to buy cosmetics.

We all used 7-point Likert scale to measure and this might cause common method variance. Future researches can use different measurement instruments in same questionnaire to avoid this bias.

Our questionnaires were handed out on the Internet which might make the samples not specific enough. Future studies can focus on specific groups (such as handing out the questionnaires around the department stores or cosmeceutical stores) to make the research results have more representatives.

We only discussed the direct relationship between the variables and the intention of buying cosmetics. Futures studies can discuss whether these variables have interaction or not.

\section{References}

[1] Guthrie, M.F. and Kim, H.S. (2008) The Relationship between Consumer Involvement and Brand Perceptions of Female Cosmetic Consumers. Journal of Brand Management, 17, 114-133. https://doi.org/10.1057/bm.2008.28

[2] Hansen, T., Risborg, M.S. and Steen, C.D. (2012) Understanding Consumer Purchase of Free-of Cosmetics: A Value-Driven TRA Approach. Journal of Consumer Behaviour, 11, 477-486. https://doi.org/10.1002/cb.1397

[3] Shamsher, R. and Chowdhury, R.A. (2012) Relationship of Demographic Characte- 
ristics with Purchasing Decision Involvement: A Study on FMCG Laundry Soaps. Journal of Business \& Retail Management Research, 6, 78-89.

[4] Gore, P., Madhavan, S., McClung, G. and Riley, D. (1994) Consumer Involvement in Nonprescription Medicine Purchase Decisions. Journal of Health Care Marketing, 14, 16-23.

[5] Truong, Y. (2009) An Evaluation of the Theory of Planned Behaviour in Consumer Acceptance of Online Video and Television Services. The Electronic Journal Information Systems Evaluation, 12, 197-206.

[6] Solomon, M.R. (2007) Consumer Behavior: Buying, Having, and Being. Pearson Prentice Hall, Upper Saddle River, NJ.

[7] Ajzen, I. (1985) From Intentions to Actions: A Theory of Planned Behavior. In: Kuhl, J. and Beckman, J., Eds., Action-Control: From Cognition to Behavior, Springer, Heidelberg, 11-39. https://doi.org/10.1007/978-3-642-69746-3_2

[8] Ajzen, I. (1991) The Theory of Planned Behavior. Organizational Behavior and Human Decision Processes, 50, 179-211. https://doi.org/10.1016/0749-5978(91)90020-T

[9] Farah, M.F. (2017) Application of the Theory of Planned Behavior to Customer Switching Intentions in the Context of Bank Consolidations. International Journal of Bank Marketing, 35, 147-172. https://doi.org/10.1108/IJBM-01-2016-0003

[10] Pikturnienè, I. and Mackelaitè, A. (2013) Attitude Formation towards Local and International Ecological Face and Body Care Brands among Lithuanian Female Consumers. Organizations and Markets in Emerging Economies, 4, 23-42.

[11] Kumar, A., Lee, H.J. and Kim, Y.K. (2009) Indian Consumers' Purchase Intention toward a United States versus Local Brand. Journal of Business Research, 62, 521-527. https://doi.org/10.1016/j.jbusres.2008.06.018

[12] Kang, J., Liu, C. and Kim, S.H. (2013) Environmentally Sustainable Textile and Apparel Consumption: The Role of Consumer Knowledge, Perceived Consumer Effectiveness and Perceived Personal Relevance. International Journal of Consumer Studies, 37, 442-452. https://doi.org/10.1111/ijcs.12013

[13] Brucks, M. (1985) The Effects of Product Class Knowledge on Information Search Behavior. Journal of Consumer Research, 12, 1-16. https://doi.org/10.1086/209031

[14] Park, C.W. and Lessig, V.P. (1981) Familiarity and Its Impact on Consumer Decision Biases and Heuristics. Journal of Consumer Research, 8, 223-231. https://doi.org/10.1086/208859

[15] Moorman, C., Diehl, K., Brinberg, D. and Kidwell, B. (2004) Subjective Knowledge, Search Locations, and Consumer Choice. Journal of Consumer Research, 31, 673-680. https://doi.org/10.1086/425102

[16] Jalilvand, M.R., Ebrahimabadi, F. and Samie, N. (2011) The Impact of Branding on Customers' Attitudes toward Banking Services (The Case of Iran's Melli Bank). International Business and Management, 2, 186-197.

[17] Tuškej, U., Golob, U. and Podnar, K. (2013) The Role of Consumer-Brand Identification in Building Brand Relationships. Journal of Business Research, 66, 53-59. https://doi.org/10.1016/j.jbusres.2011.07.022

[18] Park, C.W., Jaworski, B.J. and Maclnnis, D.J. (1986) Strategic Brand Concept-Image Management. Journal of Marketing, 50, 135-145. https://doi.org/10.2307/1251291

[19] Dolatabadi, H.R., Kazemi, A. and Rad, N.S. (2012) The Impact of Brand Personality and Sales Promotions on Brand Equity (Case Study: Cosmetic Products Retailers). International Journal of Academic Research in Business and Social Sciences, 2, 
294-309.

[20] Batra, R. and Homer, P.M. (2004) The Situational Impact of Brand Image Beliefs. Journal of Consumer Psychology, 14, 318-330. https://doi.org/10.1207/s15327663jcp1403_12

[21] Godey, B., Pederzoli, D., Aiello, G., Donvito, R., Chan P., Oh, H., Singh, R., Skorobogatykh, I.I., Tsuchiya, J. and Weitz, B. (2012) Brand and Country-of-Origin Effect on Consumers' Decision to Purchase Luxury Products. Journal of Business Research, 65, 1461-1470. https://doi.org/10.1016/j.jbusres.2011.10.012

[22] Zhang, B. and Kim, J.H. (2013) Luxury Fashion Consumption in China: Factors Affecting Attitude and Purchase Intent. Journal of Retailing and Consumer Services, 20, 68-79. https://doi.org/10.1016/j.jretconser.2012.10.007

[23] Laurent, G. and Kapfer, J.N. (1985) Measuring Consumers' Involvement Profiles. Journal of Marketing Research, 22, 41-53. https://doi.org/10.2307/3151549

[24] Houston, M.J. and Rothschild, M.L. (1978) Conceptual and Methodological Perspectives on Involvement. In: Hunt, H.K., Ed., Advances in Consumer Research 5, Association for Consumer Research, Ann Arbor, 184-187.

[25] Bloch, P.H. and Richins, M.L. (1983) A Theoretical Model for the Study of Product Importance Perceptions. Journal of Marketing, 47, 69-81. https://doi.org/10.2307/1251198

[26] McEachern, M.G. and Warnaby, G. (2008) Exploring the Relationship between Consumer Knowledge and Purchase Behavior of Value-Based Labels. International Journal of Consumer Studies, 32, 414-426. https://doi.org/10.1111/j.1470-6431.2008.00712.x

[27] Cases, A.S., Fournier, C., Dubois, P.L. and Tanner, J.F. (2010) Web Site Spill over to Email Campaigns: The Role of Privacy, Trust and Shoppers' Attitudes. Journal of Business Research, 63, 993-999. https://doi.org/10.1016/j.jbusres.2009.02.028

[28] Agarwal, S. and Singh, S. (2015) Customer Progression and Perception about Premium Men's Apparel Brands: A Case of Indian Male Professionals. Middle East Journal of Business, 10, 50-56. https://doi.org/10.5742/MEJB.2015.92598

[29] Fishbein, M. and Ajzen, I. (2010) Predicting and Changing Behavior: The Reasoned Action Approach. Psychology Press, New York.

[30] Zaichkowsky, J.L. (1994) Research Notes: The Personal Involvement Inventory: Reduction, Revision, and Application to Advertising. Journal of Advertising, 23, 59-70. https://doi.org/10.1080/00913367.1943.10673459

[31] Kaiser, H.F. (1974) An Index of Factorial Simplicity. Psychometrika, 39, 31-36. https://doi.org/10.1007/BF02291575

[32] Cohen, J. (1988) Statistical Power Analysis for the Behavioral Sciences. Lawrence Erlbaum. 